\title{
Prediction of Revenue Loss Impact on the Energy Utilities' Financial Sustainability due to Non-technical Losses using Statistical Method
}

\author{
Patricia Peya Mokoena and Antoine F. Mulaba - Bafubiandi
}

\begin{abstract}
This study presents the work done in the evaluation of revenue loss to the electricity utilities as a result of non-technical losses. It is based on the statistical modelling of electrical energy utilisation of typical households of three occupants. The energy data is generated using HOMER software, which received only the 24 hours pattern. The data is prepared into two segments of 168 and 744 samples respectively. These segments represent the number of hours in a week and 31 days months. Autoregressive-moving average model was used to develop a predictive model. The predicted energy utilisation is used to compute the revenue that the users are liable to pay the utilities. The results show that the revenue loss is insignificant when the prediction is done for smaller period. As the period of prediction increases, so is the revenue loss.
\end{abstract}

Keywords - Statistical prediction, financial losses, energy utilities; non-technical losses, financial sustainability.

\section{INTRODUCTION AND BACKGROUND}

Technical and non-technical losses are issues that affects the revenues of electricity utilities each day. However, with technical losses, the utilities can plan for them as they often include losses due to the operation of the infrastructure. Non-technical losses on the other hand, are challenging to predict as they are often related to human behaviour (Rodrigo and Gunatillaka (2019:2). According to Shabir Nawaz and Vijayvargiya (2020:24) and Arora, (2019:2), these losses could be defined as the difference between the distributed units and the amount users have failed to pay. This difference could be calculated as (Electrical India (2018:8)):

Distribution and Transmission $(T \& D)$ losses $=$ EI (Feeder's Energy Input to (Kwh) - BE (Consumer's Energy Input or Billed Energy (Kwh) x 100

These losses amount to financial loss. In (Ahmad, 2017:574) it is estimated that these losses could account for twenty-five percent $(25 \%)$ of the delivery cost of the electricity. Several methods are put forward to quantify these losses. Kumawat Gupta, Jain and Bansal (2017:589) proposes a methodology to determine losses to include assessing the recurrent cost of loss, often in yearly terms. The cost reflects production cost in terms of capacity-to-generate, consumption of fuel as well as the

Patricia Peya Mokoena and Antoine F. Mulaba - Bafubiandi, Mineral processing and technology research centre, department of metallurgy, School of mining, metallurgy and chemical engineering, Faculty of Engineering and the built environment, University of Johannesburg, POBOX 170011, Doornfontein, Johannesburg. delivery or capacity cost in the distribution and transmission networks. The prediction of this costs could enable the utilities to make informed budgeting decision (Situmbeko, 2017:98).

Consequently, this work proposes the utilization of statistical tool to predict the revenue as a result of non-technical losses. The non-payment of utility bills is considered for the non-technical losses in this study. Autoregressive-moving average (ARMA) model is used to model historic energy utilization of a typical households. The energy utilization is predicted using the model and the costs of the energy is calculated.

The remainder of the paper is organised as follows: Section 2 presents the methods used in this paper. Mathematical background and instruments used are also outlined. Section 3 presents the results obtained in this work. Their discussions and implications are also set out. In Section 4 conclusion remarks are made and future research direction is proposed.

\section{METHODS}

This study uses the quantitative research methodology. This methodology is adopted because unlike the quantitative methodology, it uses statistical, mathematical, numerical approaches as well as unprejudiced quantification or examination of all gathered data. In this work, the descriptive reserch design (statistical-descriptive model) as it offers the avenue of providing sound prediction as situation varies. The descriptive research design provides systematic data analysis on the quassi-experimental data collected with the aim of accepting or rejecting the hypothesis formulated. The data synthesis and analysis provide the test of the study hypothesis (Limatahu, Rahman \& Cipta, 2017:226).

Univariant time series (UTS) model is deployed to develop the forecasting model. This work uses the autoregressive moving average (ARMA). The ARMA model is adopted based on its previous deployment in UTS analysis (Anele 2017). The model selected consists of two parts. The first deals with the autoregression (AR) of the data and the second relate to the moving average (MA). As this model combines both the regression and the moving average, it would provide better prediction as compared to using one model at the time. This is derived from the conclusion reached in (Deb 2017) that the combination of several predictive models tends to yield better results. In addition, Zhang 2015 notes that ARMA models are capable of modelling unknown process with minimum number 
of parameters. This work adopt the notation $\operatorname{ARMA}(\mathrm{p}, \mathrm{q})$ to mathematically express the model as in equations 1-3.

$$
A R(p)=\gamma_{t}=\mu+\sum_{k=1}^{p} \varphi_{k} \gamma_{t-k}+
$$
$\varepsilon_{t}$

$$
\begin{gathered}
M A(q)=\gamma_{t}= \\
\mu+\varepsilon_{t}+\sum_{k=1}^{q} \theta_{k} \varepsilon_{t-k}
\end{gathered}
$$

$$
\begin{gathered}
\operatorname{ARMA}(p, q)=\gamma_{t}=\mu+\sum_{k=1}^{p} \varphi_{k} \gamma_{t-k}+\varepsilon_{t}+ \\
\sum_{k=1}^{q} \theta_{k} \varepsilon_{t-k}
\end{gathered}
$$

Where, $\mathrm{p}$ and $\mathrm{q}$ are the model orders, $\Phi$ is the autoregressive parameter, $\theta$ is the moving average parameter, $\mu$ is the mean value of the process, and $\varepsilon t$ is the forecast error at time $\mathrm{t}$. Yt is the observed energy utilisation at time $\mathrm{t}$ while $\mathrm{k}$ is the number of historical periods.

\begin{tabular}{|c|c|c|c|c|}
\hline EQUIPMENT & QTY & CAPACITY(W) & $\begin{array}{c}\text { OPERATIONG } \\
\text { HOURS/DAY }\end{array}$ & $\begin{array}{c}\text { ENERGY } \\
\text { DEMAND(Wh) }\end{array}$ \\
\hline Television & 1 & 48 & 6 & 288 \\
\hline DSTV & 1 & 10 & 6 & 60 \\
\hline Ceiling fan & 4 & 39.3 & 6 & 871.2 \\
\hline Incandescent & 8 & 9 & 6 & 432 \\
\hline Electric Iron & 1 & 1600 & 0.33 & 528 \\
\hline Phone & 2 & 5 & 3 & 30 \\
\hline Boiling ring & 1 & 1000 & 0.00 & 2640 \\
\hline Refrigerator & 1 & 110 & 24 & 150 \\
\hline Blender & 1 & 300 & 0.5 & \\
\hline
\end{tabular}

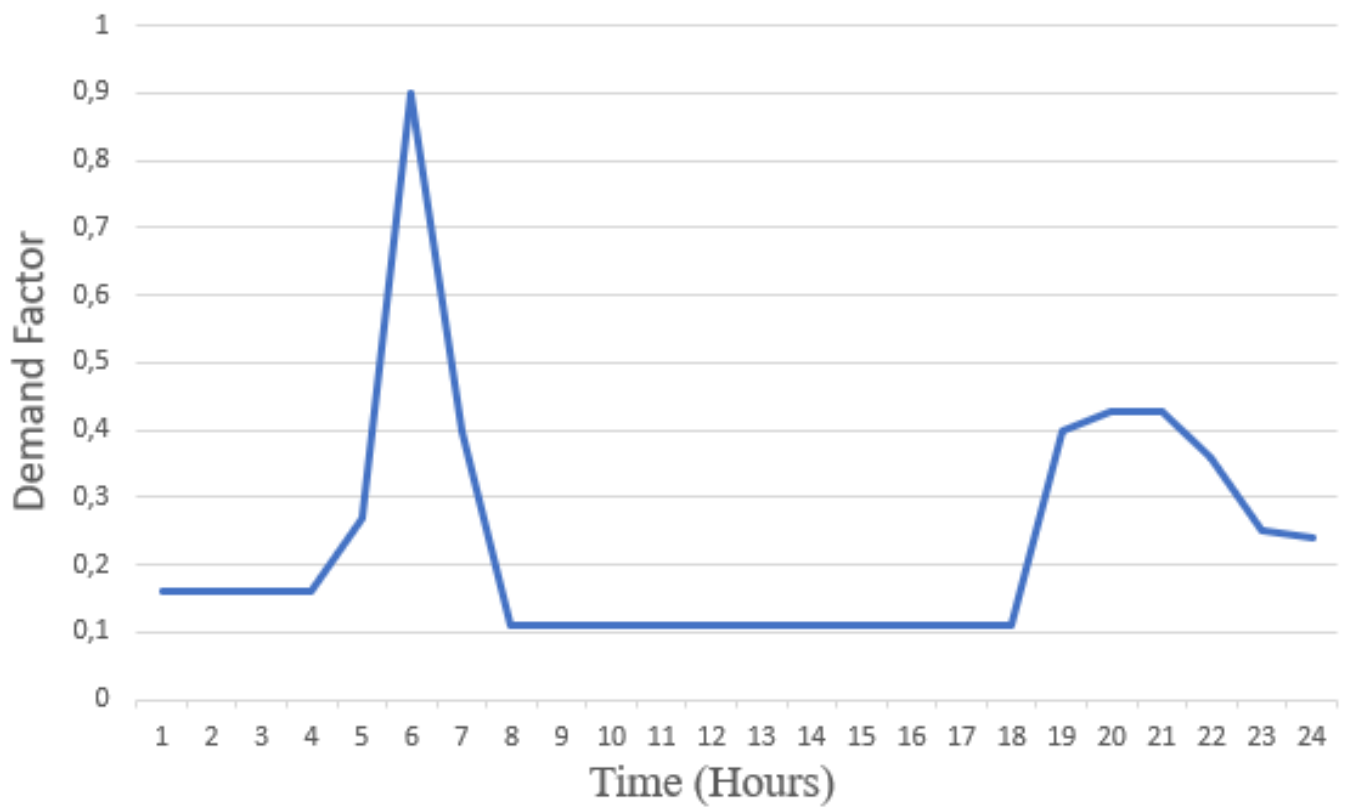

Fig. 1 Demand Pattern. Source: (Babatunde, 2019)

The demand pattern in Figure 1 was fed to HOMER simulation software to generate the quassi-experimental electrical energy utilisation dataset for eight thousand, seven
The mean square error (MSE) and root mean square error (RMSE) are used to determine the goodness of fit of the model. Equations 4-5 represents the MSE and the RMSE.

$$
M S E=\frac{1}{n} \sum_{i=1}^{n}\left(y_{i}-\widetilde{y}_{l}\right)^{2}
$$

$R M S E=\sqrt{\frac{\sum_{i=1}^{N}\left(\text { Predicted }_{i}-\text { Actual }_{i}\right)^{2}}{N}}$

The values of metrics that are close to 0 signifies that the model had a better predictions.

Materials and sampling

This work used the twenty-four (24) hours demand pattern shown in Figure 1. The demand pattern is derived from the typical energy utilisation of the household of three occupants using the equipment's shown in Table 1. 
simulations, the data is generated for the 8760 hours. The data is prepared as a univariant time series to develop a predictive model.

Research instruments

In addition to HOMER software, MATLAB/Simulink was used for the data processing. At first, the data is prepared for training. From the acquired dataset, three random segments of the data are prepared. The entries to the segment are selected randomly from the dataset to avoid the bias. For example, the first segment consists of 168 samples to represent the weekly data. The number of samples are set at 168 as the week has 168 hours. As the entries are selected randomly from the dataset, the randomisation is done such that an entry in a weekly dataset can be picked in any week of the whole dataset provided that it is in the same day and hour. The same principle was applied for monthly dataset.

\section{PRESENTATION OF FINDINGS AND DISCUSSION OF RESEARCH OUTCOMES}

Three case studies are considered during the investigation. The first case study concerns the modelling of the electrical energy utilisation based on the weekly data $(7 \times 24 \mathrm{~h}=168 \mathrm{~h})$. The second case study deals with the modelling of the electrical energy utilisation based on the monthly data $(31 \times 24 \mathrm{~h}=744 \mathrm{~h})$ while the last concerns the yearly data $(365 \times 24 \mathrm{~h}=8760 \mathrm{~h})$.

\subsection{Data preparation for training the model}

In the normal dataset, the noise with the mean and standard deviations of 1 and 0.1 respectively were added to simulate the error that may occur during the data collection. The dataset is split into two categories; (1) the training set, and (2) the test set. The percentage of the split is $70 \%$ for the training set and $30 \%$ for the test set. The trained model is tested on the $30 \%$ of the test set. The MSE and RMSE between the forecasted and the test is used to evaluate the goodness of the model.

\subsection{Case Study 1: Model Based on Weekly Data}

The predicted electrical energy utilisation and the testing set of the data are shown in Figure 3. The trained model is further examined by the prediction of its training data. Ordinarily, it is expected that the model would yield better results in this exercise as it would be predicting the data that it has already been exposed to during the training. Figure 4 show the actual training dataset and the prediction from the ARMA model. The effectiveness of the model is presented in terms of its GOF in Table 1.

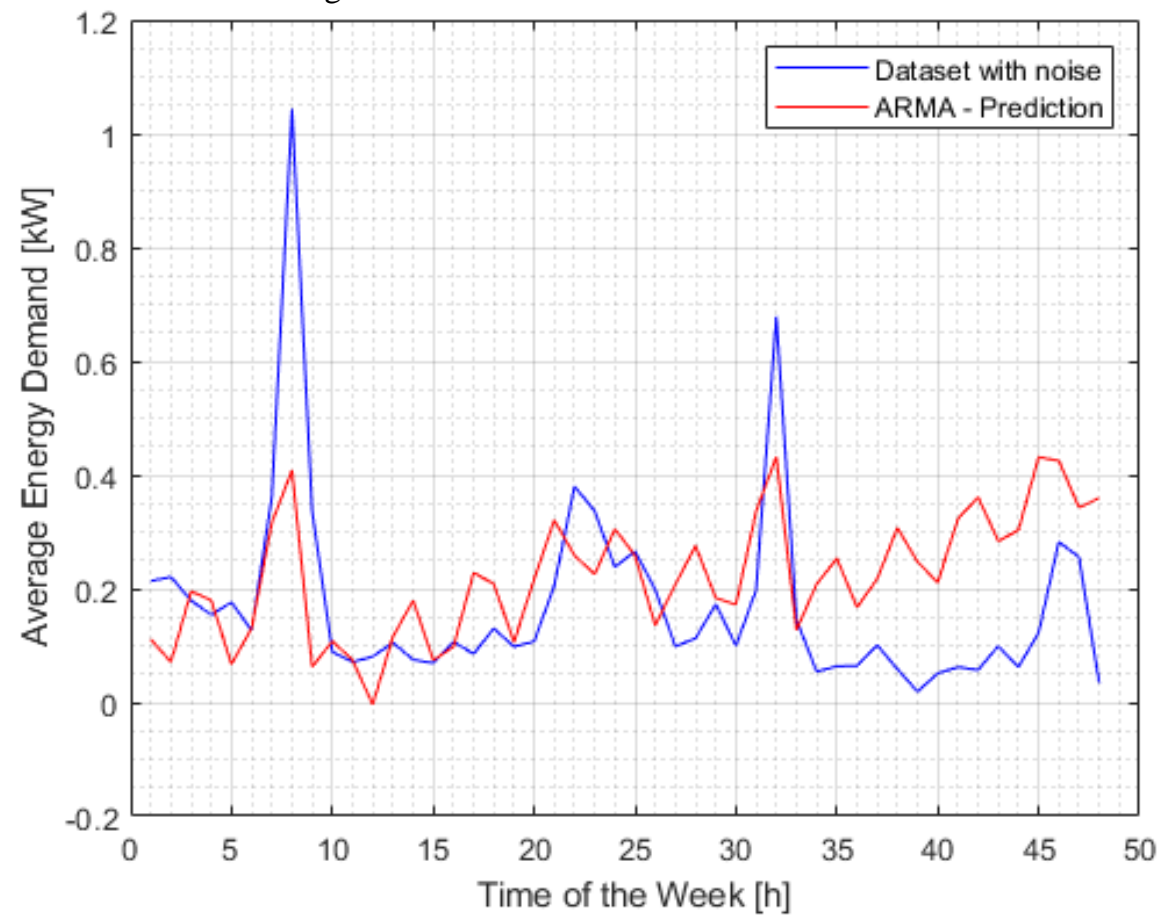

Fig. 2 The ARMA predicted Energy Utilisation and the Test Data

The Energy utilisation by ARMA is compared to test data (reserved $30 \%$ ). It is worth noting that none of the dataset entries in the reserved were used during the training of the ARMA model. 


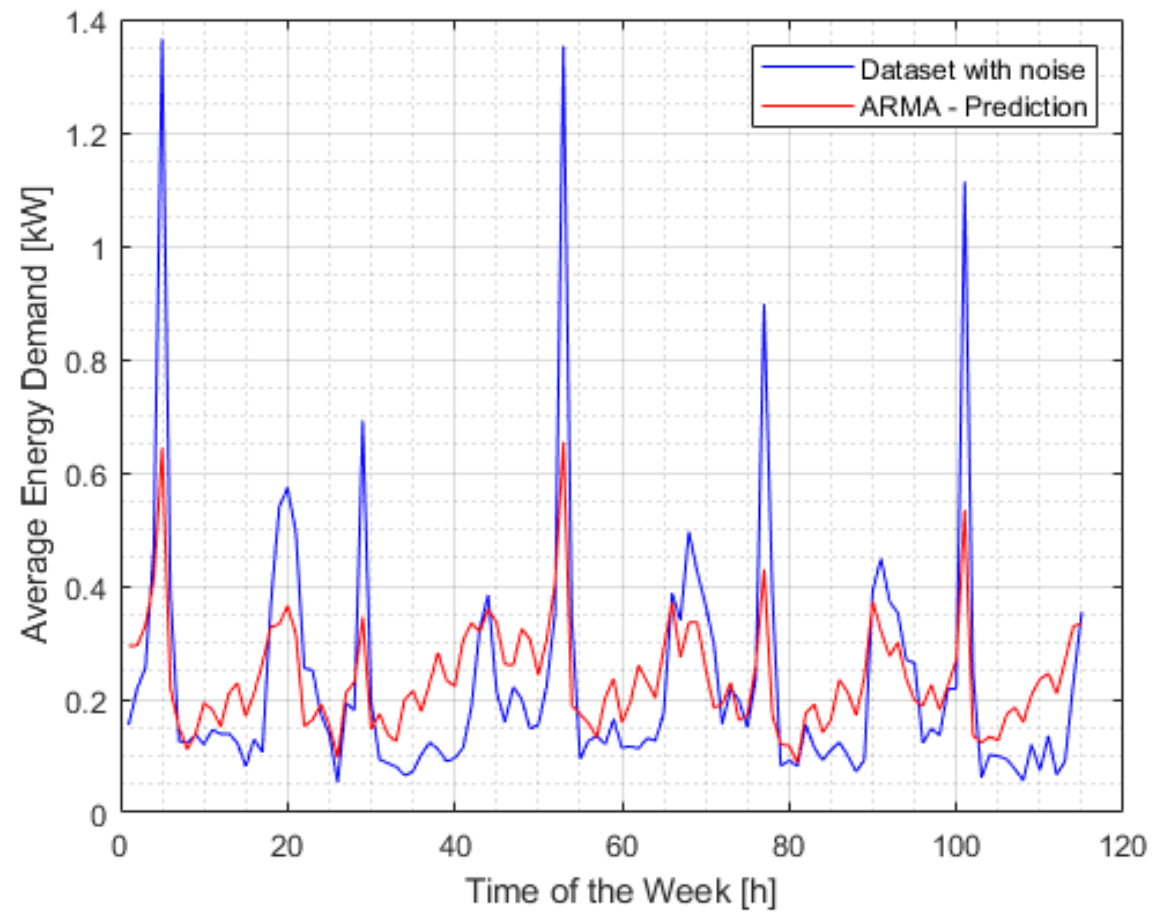

Fig. 3 The ARMA predicted Training Data and the actual Training Data.

The Energy utilisation by ARMA is compared to training data (70\% used to train the actual ARMA). It is worth noting that all of the dataset entries in the training data were used during the training of the ARMA model.

TABLE I THE MSE AND RMSE AS CALCULATE BETWEEN ARMA AND THE TEST DATA AND BETWEEN ARMA AND THE TRAINING DATA

\begin{tabular}{|l|l|l|}
\hline Dataset & MSE & RMSE \\
\hline MSE Test Data & 0.0281 & 0.1676 \\
\hline MSE Training Data & 0.0242 & 0.1556 \\
\hline
\end{tabular}

It can be seen that the model predicted the energy utilisation with an error margin that is acceptable as far as the used metrics are concerned. Furthermore, it can be seen that ARMA is more accurate when predicting the training. This is to be expected as the input to the model would be the data that was used to train the same model. The cost implication of the predicted energy utilisation is presented in Table 2. The cost is presented for two seasons, winter and summer and it is based on the approved 2020-2021 tariffs from the City of Johannesburg.

TABLE 1 THE COST TO THE UTILITY FOR SUMMER AND WINTER PERIODS. THE COST IS SEPARATED BECAUSE ACCORDING TO THE TARIFFS OF THE CITY OF JOHANNESBURG, SUMMER AND WINTER PERIODS HAVE DIFFERENT RATES

\begin{tabular}{|l|l|l|}
\hline & $\begin{array}{l}\text { Costs in R } \\
\text { (Winter) }\end{array}$ & Cost in R (Winter) \\
\hline Predicted Cost & 12.4945 & 15.7857 \\
\hline Actual Cost & 11.1644 & 12.7885 \\
\hline
\end{tabular}

It can be seen that the model predicted cost is higher than the actual cost. However, the difference is just over 1 rand for summer period. It is evident that, for winter periods the costs implication to the utilities would be higher. This is due to the higher tariff in winter as a result of higher demand. Furthermore, the costs are computed with the assumption the energy utilisation would be the same, however, it is well known that in winter, the energy utilisation tend to be higher. More details on this would be furnished in the discussion of results section.

\subsection{Case Study 2: Model Based on Monthly dataset}

The predicted electrical energy utilisation and the testing set of the data are shown in Figure 4. The trained model is further examined by the prediction of its training data. Figure 5 show the actual training dataset and the prediction from the ARMA model. The effectiveness of the model is presented in terms of its GOF in Table 3. 


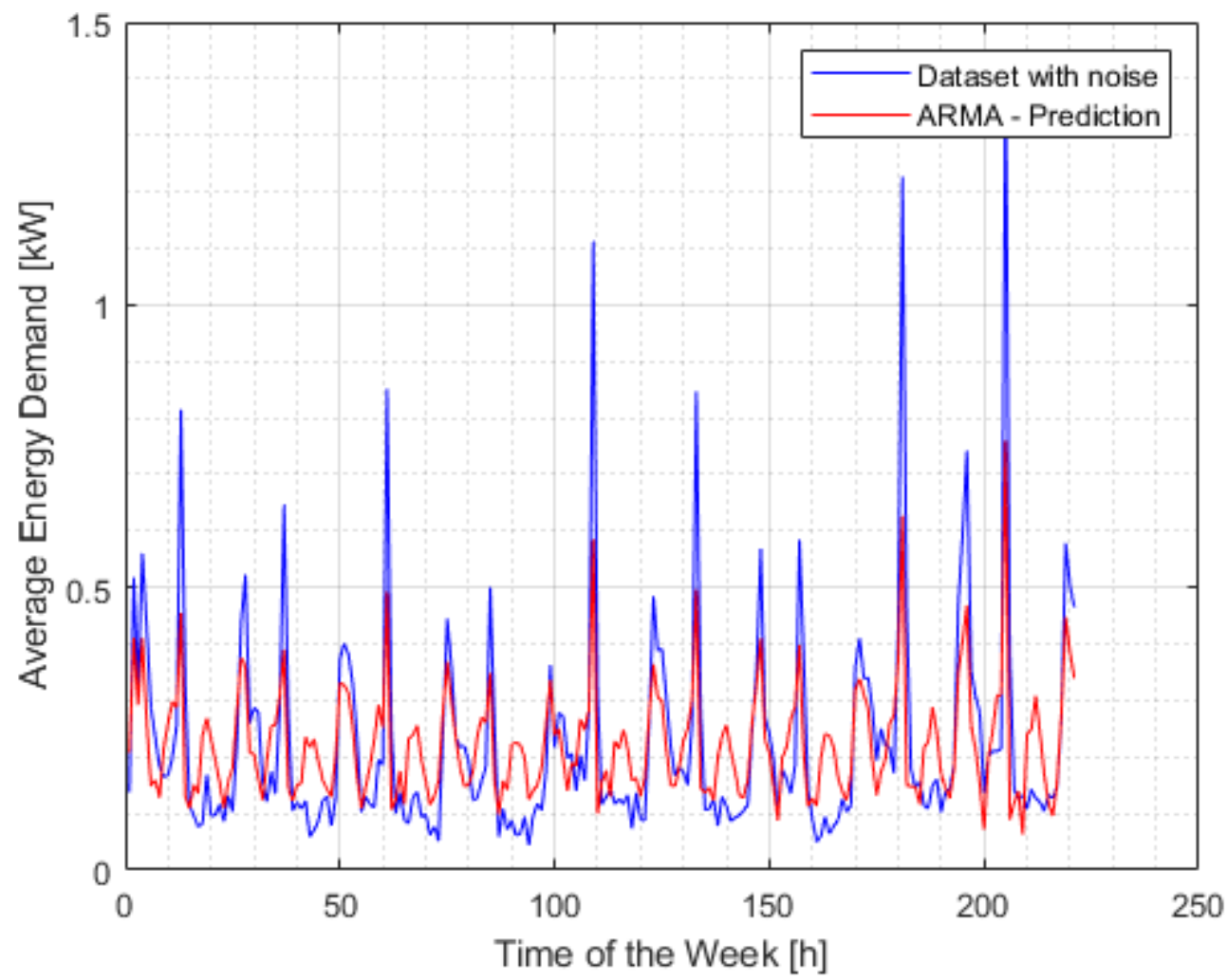

Fig. 4 The ARMA predicted Energy Utilisation and the Test Data.

The Energy utilisation by ARMA is compared to test data (reserved $30 \%$ ). It is worth noting that none of the dataset entries in the reserved were used during the training of the ARMA model.

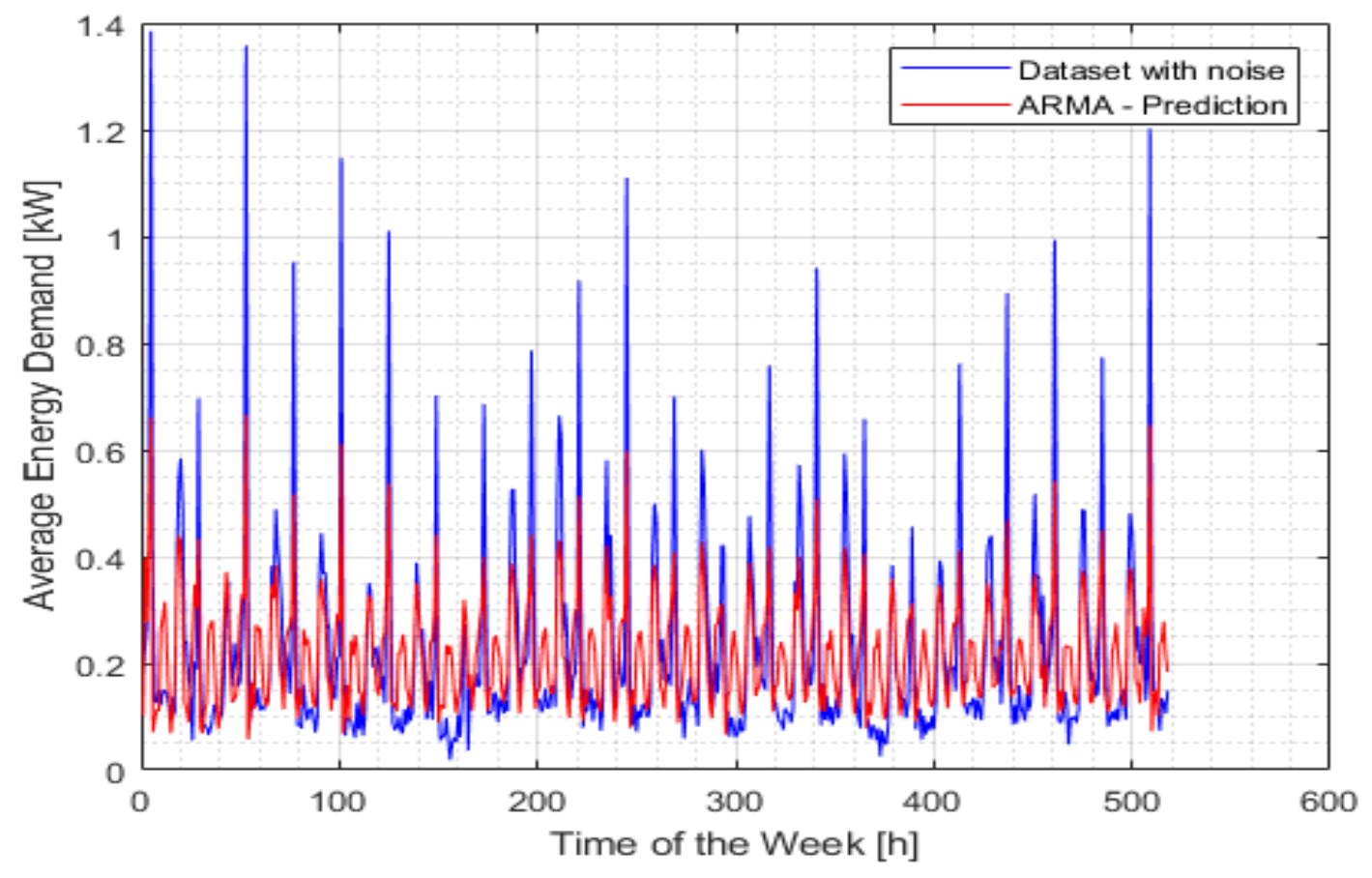

Fig. 5 The ARMA predicted Training Data and the actual Training Data.

The Energy utilisation by ARMA is compared to training data (70\% used to train the actual ARMA). It is worth noting that all of the dataset entries in the training data were used during the training of the ARMA model. 
TABLE III THE MSE AND RMSE AS CALCULATE BETWEEN ARMA AND THE TEST DATA AND BETWEEN ARMA AND THE TRAINING DATA

\begin{tabular}{|l|l|l|}
\hline Dataset & MSE & RMSE \\
\hline MSE Test Data & 0.0156 & 0.1249 \\
\hline MSE Training Data & 0.0165 & 0.1285 \\
\hline
\end{tabular}

It can be seen that the model predicted the energy utilisation with an error margin that is acceptable as far as the used metrics are concerned. Furthermore, it can be seen that in this case study, ARMA is more accurate when predicting the test data. This could be as a results that the model is exposed to more dataset during the training. In Table 4, the costs for the energy for the predicted test and the actual test dataset $(\approx 216$ hours $)$ are shown. The cost of this is evaluated for both summer and winter periods.

TABLE IV THE COST TO THE UTILITY FOR SUMMER AND WINTER PERIODS. THE COST IS SEPARATED BECAUSE ACCORDING TO THE TARIFFS OF THE CITY OF JOHANNESBURG, SUMMER AND WINTER PERIODS HAVE DIFFERENT RATES.

\begin{tabular}{|l|l|l|}
\hline & $\begin{array}{l}\text { Costs in R } \\
\text { (Winter) }\end{array}$ & \\
\hline Predicted Cost & 62.8782 & 75.0130 \\
\hline Actual Cost & 63.6490 & 75.9326 \\
\hline
\end{tabular}

In this case study, the actual cost is found to be higher as compared to the predicted cost for both summer and winter seasons. It is evident that, for winter periods the costs implication to the utilities could be detrimental. This is due to the higher tariff in winter as a result of higher demand. It is worth noting that the cost calculations are carried out with the assumption the energy utilisation would be the same, however, should the assumption be false, the cost implication could actually be higher.

\section{Discussion OF RESUlTS}

The autoregressive moving average (ARMA) model is used to predict the energy utilisation in this work. The effectiveness of the model is evaluated using two goodness of fit (GOF) metrics. It can be seen from Tables 1 and 3 show that the accuracy of the model changes when the time horizon of the dataset is changed. This finding supports the assertion made in several research works (Hamer 2015, Fumo 2015). In this study, it can be seen that the model is more accurate when the time horizon is set to 744 (Monthly).

The predicted costs of energy is presented in Tables 2 and 4. Evidently, it can be seen that should the bills remain unpaid, the utilities would experience a greater revenue loss during the winter period. This is as due to the fact that a $\mathrm{kWh}$ of energy cost more in winter as compared to summer, according to the tariffs from the City of Johannesburg (City Power Johannesburg. (2019)). In addition, it is well that that the energy demand is more in Winter (Savic 2014 and Heidarinejad
2017. In Savic 2014, it is asserted that the energy utilisation doubles during winter periods.

From Table 2, the predicted cost is found to be ZAR 15.79. Considering the conclusion of Savic 2014, the figure would be double in Winter to be ZAR 31.58. This implies that every household that does not pay for energy utilisation will be draining the utility ZAR 31.58 for every 48 hours of consumption in Winter days. Taking into account that in South Africa, Winter period has got 92 days (2208 hours), the utility would ultimately loose $\approx$ ZAR 1 452.68. This may seem insignificant considering the budgets of the utilities, however, should 100 households not service their obligations, the revenue lost quickly rises to $\approx$ ZAR 145268 per households, for 92 days only. The remaining days of the year (273 days, 6552 hours) could potential contribute $\approx$ ZAR 2299,02 to the revenue lost by the utility.

Considering the predicted cost from the model trained with Monthly data in Table 4, the revenue that the utility could lose amounts $\approx$ ZAR 75.01 and twice that in winter to be $\approx$ ZAR 150.02. This is the cost is only attributed to $\approx 216$ hours of energy utilisation per household. During the Winter months, according the model trained with the dataset with the time horizon of 744 hours, the contribution of each household that does not pay bills to the revenue loss amounts to $\approx$ ZAR 1 533,54 . The difference between this cost and the one derived from the model trained with weekly data is $\approx$ ZAR 81 . This is the result of the variation between the accuracies of the model as the time horizon of the dataset changes. The rest of the 273 days (6552 hours) could potentially contribute $\approx$ ZAR 2275.30 to the revenue lost by the utility.

It is evident from above that should the culture of non-payment spread across board; the revenue lost would result in financial unsustainable utility. In a case where the utility is a municipality, the administration would be forced to cut down on other services just to keep the lights on. This would result in tough socio-economic conditions and jobs that could have been created by those services would be lost.

\section{CONCLUSION}

In this work, an investigation was carried out in order to make prediction on the impact of non-technical loss on the financial sustainability of the utility using statistical approach. The analysis is based on the predicted energy utilisation of a typical household of three occupants. Based on the predicted energy utilisation, the monetary value is computed to estimate the loss of revenue. Evidently, the results show that the revenue loss is insignificant considering the budget of the utilities/municipalities. However, as the prediction is extrapolated over longer period, the loss becomes significant, more so if hundreds of households are considered.

Modelling the energy based on the weekly data and monthly data show slight variation in the predicted revenue loss. This observation has previously been made in the literature in a sense that, having more data results in accurate model. Nevertheless, in this work, the difference is observed to be around $2 \%$ and therefore indicating that the weekly data could be reliable in the case whereby it is the only available data. 
As this work focused on univariant time series analysis, it proposes that future work could deploy multi-variant analysis. This could be done by including the weather conditions in order to increase the dependability of the model.

\section{ACKNOWLEDGMENT}

The written authorisation from City power to conduct the research and present the manuscript is acknowledged. The authors are thankful to the university of Johannesburg for the overhead cover for A.F. M-B.

\section{DECLARATION OF CONFLICT OF INTEREST}

The authors declare no personal benefit deriving from the findings of this research.

\section{AUTHORS' CONTRIBUTIONS}

Patricia Mokoena came up with the topic and conducted the research work based on her work exposure and platform while the study was supervised by Antoine Mulaba who initiated, structured and ensured the academic background of the manuscript.

\section{REFERENCES}

[1] Rodrigo, A.S. and Gunatillaka, M.D.P.R., 2019. An Effective Method of Segregation of Losses in Distribution Systems. ENGINEER, 52(02), pp.1-14.

https://doi.org/10.4038/engineer.v52i2.7349

[2] Shabir, M., Nawaz, S., \& Vijayvargiya, A. 2020. Voltage Stability Enhancement using SVC in PSCAD Software. Majlesi Journal of Mechatronic Systems, 9(1), 23-30.

[3] Electrical India. 2018. Losses in Distribution \& Transmission Lines Electrical India Magazine on Power \& Electrical products, Renewable Energy, Transformers, Switchgear \& Cables. Available: https://www.electricalindia.in/losses-in-distribution-transmission-lines/ [2020, May 24],pp.8-9

[4] Ahmad, T., 2017. Non-technical loss analysis and prevention using smart meters. Renewable and Sustainable Energy Reviews, 72, pp.573-589. https://doi.org/10.1016/j.rser.2017.01.100

[5] Kumawat, M., Gupta, N., Jain, N. and Bansal, R.C., 2017. Swarm-intelligence-based optimal planning of distributed generators in the distribution network for minimizing energy loss. Electric Power Components and Systems, 45(6), pp.589-600. https://doi.org/10.1080/15325008.2017.1290713

[6] Situmbeko, S.M., 2017. Decentralised energy systems and associated policy mechanisms - A review of Africa. Journal of Sustainable Bioenergy Systems, 7(03), p.98. https://doi.org/10.4236/jsbs.2017.73008

[7] Limatahu, N.A., Rahman, N.A. and Cipta, I., 2017. The influence of practicum video with electronic module toward process skills for stoichiometry materials of the grade $\mathrm{x}$ of SMAN 2 Tidore Islands. Jurnal Pendidikan Kimia, 9(1), pp.225-228. https://doi.org/10.24114/jpkim.v9i1.6183

[8] Anele, A. O., Hamam, Y., Abu-Mahfouz, A. M., \& Todini, E. (2017). Overview, comparative assessment and recommendations of forecasting models for short-term water demand prediction. Water, 9(11), 887. https://doi.org/10.3390/w9110887

[9] Deb, C., Zhang, F., Yang, J., Lee, S. E., \& Shah, K. W. (2017). A review on time series forecasting techniques for building energy consumption. Renewable and Sustainable Energy Reviews, 74, 902-924. https://doi.org/10.1016/j.rser.2017.02.085

[10] Zhang, Z., \& Moore, J. C. (2015). Chapter 8-Autoregressive Moving Average Models. Mathematical and Physical Fundamentals of Climate Change (239-290). Boston: Elsevier. https://doi.org/10.1016/B978-0-12-800066-3.00008-5

[11] Babatunde, O. M., Munda, J. L., \& Hamam, Y. (2019, October). Photovoltaic system sizing for household use: effects of temperature, orientation and sun tracking. In 2019 Open Innovations (OI) (pp. 190-195). IEEE.

https://doi.org/10.1109/OI.2019.8908227

[12] Harmer, L. C., \& Henze, G. P. (2015). Using calibrated energy models for building commissioning and load prediction. Energy and Buildings, 92, 204-215.

https://doi.org/10.1016/j.enbuild.2014.10.078

[13] Fumo, N., \& Biswas, M. R. (2015). Regression analysis for prediction of residential energy consumption. Renewable and sustainable energy reviews, 47, 332-343.

https://doi.org/10.1016/j.rser.2015.03.035

[14] City Power Johannesburg. (2019) Schedule of Approved Electricity Tariffs for FY2019/20

[15] Savić, S., Selakov, A., \& Milošević, D. (2014). Cold and warm air temperature spells during the winter and summer seasons and their impact on energy consumption in urban areas. Natural hazards, 73(2), 373-387. https://doi.org/10.1007/s11069-014-1074-y

[16] Heidarinejad, M., Cedeño-Laurent, J. G., Wentz, J. R., Rekstad, N. M., Spengler, J. D., \& Srebric, J. (2017). Actual building energy use patterns and their implications for predictive modeling. Energy Conversion and Management, 144, 164-180.

https://doi.org/10.1016/j.enconman.2017.04.003 